ISSN: 2595-2498

\title{
USO DA REPRESENTAÇÃO SOCIAL PARA AVALIAR A APRENDIZAGEM DOS ESTUDANTES NO ENSINO DE QUÍMICA
}

\section{USE OF SOCIAL REPRESENTATION TO EVALUATE THE STUDENTS' LEARNING IN CHEMISTRY TEACHING}

\author{
Autores: \\ ${ }^{1}$ Dr. Gesivaldo Jesus Alves de Figueirêdo \\ Doutor em Engenharia Agrícola e Professor da Licencatura em Química, IFPB - campus João Pessoa - \\ Paraíba, Brasil. \\ ${ }^{2}$ Patrícia Brito Souza da Nóbrega \\ Mestranda em Engenharia Civil e Ambiental da Universidade Federal da Paraíba, UFPB - campus João \\ Pessoa - Paraíba, Brasil. \\ ${ }^{3}$ Dr. ${ }^{a}$ Lastenia Ugalde Meza \\ Doctora en Ciencias mención Química, Profesora de Química y Ciencias, Licenciada en Química, \\ Químico, Coordinadora Docente, Departamento de Química, Facultad de Ciencias, UPLA - Valparaiso, \\ Chile. \\ ${ }^{4}$ Dr. Jaime Patricio Leiva Núñez \\ Doctor en Didácticas de las Ciencias de la educación, Profesor de Biología y Ciencias, Licenciado en \\ Educación, Diplomado en Estadística y Computación Educativa, Coordinador Sello Tic de la \\ Universidad de Playa Ancha, Departamento de Matemática y Estadística, Facultad de Ciencias, UPLA \\ - Valparaíso, Chile.
}

Orientador:

Dr. Gesivaldo Jesus Alves de Figueirêdo

Contato do autor principal:

gesivaldo.figueiredo@ifpb.edu.br

Av. $1^{\circ}$ de Maio, 720, Jaguaribe, João Pessoa, PB - Brasil - CEP: 58.015-430. 


\title{
USO DA REPRESENTAÇÃO SOCIAL PARA AVALIAR A APRENDIZAGEM DOS ESTUDANTES NO ENSINO DE QUÍMICA
}

\author{
USE OF SOCIAL REPRESENTATION TO EVALUATE THE STUDENTS' LEARNING IN \\ CHEMISTRY TEACHING
} Gesivaldo Jesus Alves de Figueirêdo ${ }^{1}$; Patrícia Brito Souza da Nóbrega² ${ }^{2}$ Lastenia Ugalde Meza ${ }^{3}$;
Jaime Patricio Leiva Núñez ${ }^{4}$

Resumo: As representações sociais informam as concepções que os indivíduos possuem a respeito de um tema, permitindo interpretar e discutir a influência do meio sobre o pensamento do coletivo e, assim, serem utilizadas como instrumento avaliativo da aprendizagem e levantamento dos conhecimentos prévios dos educandos sobre determinada temática a ser abordada. Nessa perspectiva, a pesquisa objetivou avaliar a representação social dos estudantes do $2^{\circ}$ ano do Curso Técnico de Controle Ambiental Integrado ao Ensino Médio do IFPB, Campus João Pessoa, no ensino de Química, por meio da técnica de evocação livre de palavras, a qual permitiu orientar e avaliar a contextualização da Química com a temática qualidade de água, bem como identificar que, nos resultados obtidos das palavras evocadas após a aplicação da metodologia houve uma aprendizagem significativa e a correlação mais efetiva dos conteúdos químicos com o cognitivo dos estudantes.

Palavras-chave: Contextualização, Ensino de Química, Representação Social, Tratamento de água.

Abstract: The social representations inform the conceptions that individuals have about a topic, allowing interpret and discuss the influence of the environment on the thinking of the collective and, thus be used as assessment tool of learning and raising the previous knowledge of students on a given topic to be approached. In this perspective, the research aimed to evaluate the social representation of students of 2nd year of the Technical Course of Integrated Environmental Control to IFPB high school, Campus João Pessoa, in the teaching of chemistry, by free evocation technique of words which led to guide and assess the context of chemistry with the theme of water quality, and identify that the results of evoked words after the application of the methodology, there was a significant learning and more effective correlation of chemical content with students' cognitive.

Keywords: Contextualization, Chemistry Teaching, Social Representation, Water Treatment.

\section{INTRODUÇÃO}

A Teoria das Representações Sociais vem sendo utilizada para analisar as distintas visões e conhecimentos prévios de estudantes acerca de determinadas temáticas abordadas em sala de aula, visando verificar, assim, as representações sociais deles a respeito dos seus pensamentos do que já lhe foi apresentado durante a vida escolar e, contudo considerando seus conhecimentos e experiências pessoais.

Sabe-se que a Teoria das Representações Sociais é feita a partir da escolha de uma ideia indutora para dela ser feita a representação por alguém e, em sequência, a realização de análises e elaboração de conclusões do que o objeto desempenha sobre o sujeito, daí é possível avaliar se ocorrem alterações na estrutura central da representação social. Neste contexto a teoria das representações sociais deve refletir que a cognição do sujeito pode ser sim objeto de estudo (CORTES JUNIOR; CORIO; FERNANDEZ, 2009, p.46). 
Dessa maneira, considerando que aprendizagem significativa remete à inserção do conceito aprendido na estrutura cognitiva do alunado plausível inferir que essa teoria pode ser utilizada no meio educacional como método avaliativo da aula ministrada, verificando se ocorreu uma aprendizagem significativa com a metodologia utilizada, ou aplicada inicialmente para averiguar os conhecimentos prévios dos estudantes, reconhecendo melhor suas ideias acerca de determinado tema e, assim, nortear melhorias na didática de aulas a serem ministradas.

Com base nisso, verifica-se que a sondagem do conhecimento prévio dos educandos permite orientar a contextualização da temática qualidade de água no ensino de Química, tendo em vista que as etapas e procedimentos de tratamento de água fazem com que sejam retiradas as impurezas e ocorra a adequação das substâncias químicas dentro de até o máximo permitido na legislação vigente, oferecendo, assim, qualidade à água sem causar eventuais malefícios nas atividades que podem ser aplicadas e no consumo direto pelas pessoas, do mesmo modo que esse contexto possui ampla correlação com os conteúdos químicos a serem abordados.

Dessa forma, o presente trabalho propôs realizar um estudo da representação social dos estudantes da turma do $2^{\circ}$ ano do Curso Técnico de Controle Ambiental Integrado ao Ensino Médio do Instituto Federal de Educação, Ciência e Tecnologia da Paraíba - IFPB, Campus João Pessoa, utilizando a técnica de evocação livre de palavras como método avaliativo dos conhecimentos prévios e da metodologia aplicada.

\section{FUNDAMENTAÇÃO TEÓRICA}

\section{Representação Social}

As representações sociais se referem a fenômenos que nos cercam e a partir deles obtemos uma concepção, isto é, formamos opiniões próprias a respeito de um determinado assunto de acordo com as vivências do cotidiano e conhecimentos prévios (JODELET, 2001).

Consequentemente, as representações sociais analisam e explicam a nossa visão de mundo acerca de determinado assunto em análise, e a partir delas podemos chegar a conclusões sobre o pensamento coletivo de um grupo em estudo.

Elas nos guiam na maneira de nomear e definir conjuntamente os diferentes aspectos de nossa realidade diária, no modo de interpretar esses aspectos, tomar decisões e, eventualmente, posicionar-se frente a eles de forma defensiva. (JODELET, 1989, p. 17).

Logo, colocando um indivíduo diante de uma determinada situação, ele, para poder compreender, leva em conta todos os conhecimentos adquiridos durante a vida, que pode ser 
caracterizado como senso comum, e que sofreram influência do ponto de vista científico, étnico e popular, se diferenciando de acordo com o grupo social a que pertence.

As representações sofrem influência conforme esses fatores, então, dependendo da interação que determinada pessoa tem naquele meio, irá apresentar distintas representações sociais à medida que tiver contato com novas informações. Se estas tiverem fortes ligações com seu cognitivo, provocará mudanças em suas concepções anteriores, podendo inferir que a opinião de um indivíduo não é imutável, algo pronto e acabado, e que admite as interações sociais com o meio e os demais conhecimentos que vier a ter contato. Contudo, a ampliação do conhecimento dos estudantes advindo a partir da aprendizagem significativa pode ser remetida por sua inserção nas estruturas mais centrais da representação social.

De acordo com Jodelet, Guará e Lisbôa, a Teoria das Representações Sociais é descrita como: “[...] uma forma de conhecimento, socialmente elaborada e partilhada, com um objeto prático e que contribui para a construção de uma realidade comum a um conjunto social." (JODELET, 1989, p. 22).

Isto significa que é aceita como um senso comum, portanto, é uma forma de objeto regular a se estudar como qualquer outra. Consequentemente, essa teoria vem crescentemente sendo usada como ferramenta de estudo para analisar as questões educacionais quanto ao aprendizado, considerando o incremento sócio-histórico-cultural nelas, a partir de distintas visões de mundo e conhecimentos prévios. Dessa forma, podem-se analisar as representações dos conhecimentos dos educandos, pois seus conceitos estão diretamente relacionados ao contexto sócio-histórico-cultural (COLL et al., 2000).

A análise dessa teoria é feita a partir da escolha de um propósito para o qual é feita a representação pelos indivíduos e que se estruturam em torno de algo que seja central, dessa forma, caracterizando-se como constituinte do núcleo central e que determina as interpretações (SÁ, 1996).

Enquanto que os núcleos centrais são determinantes para se descrever uma representação social do grupo, dela podem ser extraídos os periféricos também, os quais sustentam e promovem as interações dos indivíduos com o meio, estabelecendo, assim, a relação entre a cognição e a vivência do indivíduo (ABRIC, 1994b).

Para elaborar este levantamento de distinção entre quais são caracterizados como elementos centrais e quais são os periféricos, desta forma estruturando toda aquela representação obtida, existem diversas técnicas, a exemplo, a técnica de evocação livre de palavras (CORTES JUNIOR; CORIO; FERNANDEZ, 2009). 


\section{Representação Social Na Educação}

Os professores desempenham um papel importante na formação das concepções dos estudantes, tanto nos conteúdos que ministra como a forma didática adotada para abordá-los. Dessa forma, as representações sociais podem ser utilizadas para se realizar um levantamento dos conhecimentos prévios dos educandos sobre determinada temática a ser abordada posteriormente, o que auxilia diretamente em como atingir os futuros conhecimentos de forma mais eficaz no cognitivo.

Com isso, a forma didática a ser adotada influencia no aprendizado dos discentes, verificando que afeta diretamente as representações a serem coletadas em consecutivo. Assim, uma aula motivadora e dinâmica obterá melhores elementos centrais das representações do que uma aula tradicional puramente expositiva, compelida a transmitir conteúdos.

Além de que para desenvolver melhor os conteúdos em sala de aula, é imprescindível conhecer os estudantes, como expectativas de estudo e futuro profissional, do mesmo jeito suas dificuldades de aprendizado, afinal cada pessoa apresenta distintas realidades (FRANCO; NOVAES, 2001).

Considera-se que as representações sociais são pouco utilizadas pelos educadores, porém é uma importante ferramenta na área educativa e que pode ser usada de forma analítica para investigar o sistema de ensino adotado e a estrutura social em que estão (FRANCO; NOVAES, 2001).

\section{Técnica De Evocação Livre De Palavras}

A técnica de evocação livre de palavras é uma das formas de realizar o levantamento da representação social dos estudantes, a fim de se identificar os elementos centrais, intermediários e os periféricos com o propósito de apontar as concepções e, assim, observar, analisar, interpretar e discutir os resultados da turma coletivamente e individualmente (CORTES JUNIOR; CORIO; FERNANDEZ, 2009).

Essa técnica consiste em solicitar aos educandos que, a partir de um termo indutor, mencionem palavras que lhes vêm à mente que representem e signifiquem o termo (SÁ, 1996).

Nesse método, as palavras são organizadas de acordo com a frequência e a ordem de importância em que são evocadas, o que permite poder classificar os termos de acordo com a ordem de importância atribuída pelo sujeito da pesquisa, possibilitando a identificação do núcleo central para aquela representação social (CORTES JUNIOR; CORIO; FERNANDEZ, 2009). 
A frequência (f) é o número de vezes que aquela determinada palavra aparece em todas as evocações coletadas, enquanto a ordem média de evocação (OME) é a disposição que esta determinada palavra ocupa dentro das evocações como um todo. Sendo essas análises feitas para cada termo distinto evocado (CORTES JUNIOR; CORIO; FERNANDEZ, 2009).

De acordo com Cortes Junior, Corio e Fernandez (2009), a OME é calculada por meio da seguinte fórmula:

$$
O M E=\frac{\sum_{1}^{n} n \times\left(\mathrm{n}^{\mathrm{o}} \text { de evocações em } n^{\text {esimo }} \text { lugar }\right)}{f}
$$

Observando a fórmula acima, conclui-se que quanto maior a frequência que determinada palavra foi evocada, acarreta em um menor valor de OME, que, consequentemente, reflete no seu enquadramento no núcleo central.

Por meio dessa técnica, há a análise de cada termo de forma individual, com a ordem que cada indivíduo atribui no todo de suas evocações, e de forma coletiva quando contabilizado sua frequência. Esses dois critérios, posteriormente, permitem adequar os termos em distintos núcleos (central, intermediário e periférico) da representação social (CORTES JUNIOR; CORIO; FERNANDEZ, 2009).

O enquadramento das palavras em elementos centrais, intermediários ou periféricos depende do valor que cada uma possui de frequência e ordem média de evocação, conforme descrito na Tabela 1.

TABELA 1 - Critérios para classificação dos termos nos distintos núcleos.

\begin{tabular}{cc}
\hline Elementos Centrais & Elementos Intermediários \\
\hline $\mathrm{f}>$ média & $\mathrm{f}>$ média \\
$\mathrm{OME}<$ média & $\mathrm{OME}>$ média \\
Elementos Intermediários & Elementos Periféricos \\
$\mathrm{f}<$ média & $\mathrm{f}<$ média \\
$\mathrm{OME}<$ média & $\mathrm{OME}>$ média \\
\hline
\end{tabular}

Fonte: CORTES JUNIOR; CORIO e FERNANDEZ, 2009.

Desta forma, podem-se encontrar os elementos centrais e, assim, estabelecer conexões visando o entendimento e discussão da representação social para aquela temática apresentada pelas concepções de um determinado grupo.

Logo, o presente trabalho visou analisar o uso da representação social para avaliar os conhecimentos prévios dos estudantes e o nível de compreensão quanto à temática abordada. 


\section{METODOLOGIA}

Para o desenvolvimento da metodologia do presente trabalho foi utilizado a Teoria das Representações Sociais para analisar e explicar as concepções acerca de determinado assunto, e a técnica de evocação livre de palavras como ferramenta de coleta de dados.

Logo, o público alvo escolhido para participar da pesquisa foi a turma do $2^{\circ}$ ano do Curso Técnico de Controle Ambiental Integrado ao Ensino Médio do Instituto Federal de Educação, Ciência e Tecnologia da Paraíba - IFPB (Campus João Pessoa), devido ao fato dos conteúdos de Química (interação química, ligações químicas e processos de separação de misturas) serem ministrados nesse ano e a aplicabilidade direta com a vivência técnica, corroborando para uma maior associação com a prática profissional e o cotidiano.

Considerando a menor idade dos estudantes, foram assinados por seus responsáveis o Termo de Consentimento Livre e Esclarecido autorizando a participação na aplicação da pesquisa.

A partir do registro dessa autorização o plano de trabalho passou a ser executado, iniciando-se com a aplicação da técnica de evocação livre de palavras, sendo escrito no quadro o termo motivador "tratamento de água" e explicado que a técnica consistia que o educando, a princípio, relacionasse cinco (5) palavras com o termo motivador, depois elencasse essas palavras em ordem de importância, considerando-se a posição um (1) como a mais importante e a cinco (5) como a menos importante.

Por último, foi solicitado que para cada termo evocado, os estudantes construíssem uma frase que explicasse o motivo pelo qual escolheram tal palavra relacionada ao termo motivador e, assim, ficasse clara a análise e interpretação das representações sociais.

As evocações feitas foram contabilizadas com base na técnica de evocação livre de palavras, na qual se somam a frequência (f) com que cada palavra foi evocada de acordo com o nível de importância atribuído e a significação atribuída por eles.

Depois, foi calculada a ordem média de evocação (OME) para saber a disposição que uma determinada palavra ocupava dentro das evocações, a fim de se identificar os elementos centrais, intermediários e periféricos, conforme Tabela 1.

Diante desses critérios de classificação, foi possível analisar os elementos centrais para discutir a representação social dos estudantes quanto à temática qualidade de água, investigando as questões educacionais no tocante ao aprendizado, considerando o aspecto sócio-históricocultural nelas, de acordo com distintos conhecimentos prévios (CORTES JUNIOR; CORIO; FERNANDEZ, 2009). 
Após essa análise, foram ministrados, durante duas aulas, de forma dialogada, os conteúdos químicos (interação química, ligações químicas e processos de separação de misturas) contextualizados com a temática qualidade de água.

Por meio de uma aula dialogada permite-se problematizar a aula, avaliando o conhecimento prévio dos educandos e explanando os futuros conhecimentos de forma a correlacioná-los e terem maior ligação no cognitivo (AUSUBEL, 2001).

Esse processo de aprendizagem permite que o estudante seja ativo, pois tem a ação e reflexão dos conteúdos, prevalecendo a "construção" do conhecimento e promovendo uma aprendizagem significativa para o sujeito.

A partir da abordagem contextualizada, foi correlacionada a teoria e a prática, visando à aplicação dos conteúdos em uma situação do cotidiano, a fim de torná-los tangíveis, favorecendo uma aprendizagem significativa, além de relacioná-los com a vivência do curso técnico.

Por fim, para avaliar a metodologia adotada foi aplicada novamente a técnica de evocação livre de palavras para o termo motivador "tratamento de água", recolhidas, contabilizadas, analisadas e interpretadas às ideias prévias dos estudantes alvo da pesquisa quanto as suas concepções, conforme a aplicação inicial.

Em termos de quantitativo para a análise da representação social dessa turma, pôde-se contar na aplicação inicial da técnica com a participação de trinta e sete (37) educandos e ao fim da aplicação da pesquisa houve a participação de vinte e sete (27).

\section{RESULTADOS E DISCUSSÃO}

Na aplicação inicial da técnica de evocação livre de palavras para o termo motivador "tratamento de água" foi avaliada, quantitativamente, cada palavra evocada pelos estudantes, levando em consideração a frequência (f), de acordo com o nível de importância atribuído, e calculada a ordem média de evocação (OME) obtida para cada termo, com base na frequência total e o nível importância.

De acordo com as palavras obtidas pelos trinta e sete (37) estudantes dessa turma do $2^{\circ}$ ano para o termo motivador "tratamento de água" foi obtido uma frequência média de palavras evocadas de $f=2,98$, enquanto a ordem média de evocação foi de $\mathrm{OME}=3,11$. Assim, esses valores se referenciaram como parâmetros limites para o enquadramento dos termos em elementos centrais, intermediários e periféricos, podendo ser projetada a Tabela 2. 
TABELA 2 - Classificação das palavras evocadas para "Tratamento de água". (Fonte: Própria)

\begin{tabular}{|c|c|c|c|c|c|}
\hline \multicolumn{3}{|c|}{ ELEMENTOS CENTRAIS } & \multicolumn{3}{|c|}{ ELEMENTOS INTERMEDIÁRIOS } \\
\hline \multicolumn{3}{|c|}{ f $>2,98 \quad$ OME $<3,11$} & \multicolumn{3}{|c|}{ f $>2,98 \quad$ OME $>3,11$} \\
\hline Palavras & f & OME & Palavras & f & OME \\
\hline Análise & 8 & 2,13 & Processos & 6 & 3,17 \\
\hline Limpeza & 18 & 2,61 & Bactéria & 4 & 4,50 \\
\hline Química & 3 & 2,00 & Esgoto & 8 & 3,63 \\
\hline Saúde & 14 & 2,50 & Poluição & 7 & 3,86 \\
\hline Tratar & 3 & 2,00 & Potável & 4 & 3,75 \\
\hline Conservação & 4 & 2,25 & Cuidar & 4 & 3,25 \\
\hline Saneamento & 4 & 2,75 & Hidrologia & 3 & 4,00 \\
\hline Vida & 10 & 2,40 & Sujeira & 4 & 4,75 \\
\hline Rio & 4 & 3,00 & Cloro & 3 & 3,33 \\
\hline CAGEPA & 3 & 3,00 & Estudo & 3 & 3,33 \\
\hline Qualidade & 4 & 2,75 & Composição & 3 & 4,33 \\
\hline Natureza & 3 & 2,00 & Reaproveitamento & 3 & 3,67 \\
\hline Estação & 3 & 1,00 & Consumo & 3 & 3,67 \\
\hline Água & 4 & 2,75 & Filtração & 3 & 4,33 \\
\hline Conscientização & 3 & 1,33 & & & \\
\hline \multicolumn{3}{|c|}{ ELEMENTOS INTERMEDIÁRIOS } & \multicolumn{3}{|c|}{ ELEMENTOS PERIFÉRICOS } \\
\hline \multicolumn{3}{|c|}{ f $<2,98 \quad$ OME $<3,11$} & \multicolumn{3}{|c|}{ f $<2,98 \quad$ OME $>3,11$} \\
\hline Palavras & $\mathbf{f}$ & OME & Palavras & f & OME \\
\hline Ambiente & 2 & 3,00 & & & \\
\hline Bacias & 1 & 1,00 & Poluição & 2 & 3,50 \\
\hline Manutenção & 1 & 2,00 & Observação & 1 & 4,00 \\
\hline Essencial & 2 & 2,50 & Importante & 2 & 4,00 \\
\hline Soluções & 1 & 2,00 & Técnico & 1 & 5,00 \\
\hline Necessidade & 2 & 2,00 & Sobrevivência & 1 & 4,00 \\
\hline Trabalho & 1 & 3,00 & Empresa & 1 & 4,00 \\
\hline Laboratório & 1 & 1,00 & Destilação & 1 & 5,00 \\
\hline Higiene & 1 & 3,00 & Substâncias & 1 & 4,00 \\
\hline Bonita & 1 & 1,00 & Molhada & 1 & 4,00 \\
\hline Sais & 1 & 3,00 & Máquina & 1 & 5,00 \\
\hline Minerais & 1 & 2,00 & Recurso & 1 & 4,00 \\
\hline Dever & 1 & 1,00 & Técnica & 1 & 5,00 \\
\hline Decantação & 1 & 2,00 & Investimento & 2 & 4,00 \\
\hline Restauração & 1 & 3,00 & Dessalinização & 1 & 4,00 \\
\hline Economia & 1 & 1,00 & Aproveitamento & 1 & 5,00 \\
\hline Reservatório & 1 & 3,00 & Valorização & 1 & 5,00 \\
\hline
\end{tabular}

O uso dessa técnica possibilitou a identificação do núcleo central das representação social dos discentes para esse termo motivador, constatando na Tabela 2 que os estudantes possuem concepções características do senso comum a respeito da temática tratamento de água. 
Isso pode ser constatado nas palavras evocadas pelos estudantes e as respectivas frases que permite interpretar a representação social, na qual compreende-se que os estudantes, em relação à temática, restringem-se mais a entender onde é realizado tal tratamento, considerando que é útil para a vida e que diante da atual problemática de escassez veem o tratamento como uma forma de reaproveitamento das águas já usadas.

Esse contexto é verificado em outros trabalhos que analisam as representações sociais de estudantes, nos quais há a corroboração de que as representações sociais dos estudantes a respeito dos conceitos científicos estão atreladas a conceitos cotidianos (CORTES JÚNIOR, 2008 e SCHAFFER, 2007).

Então, apesar de terem o Ensino Médio integrado ao Curso Técnico em Controle Ambiental, o que viabiliza a ampliação das possíveis abordagens e aplicabilidades dos conteúdos não só da disciplina de Química como das demais disciplinas com a vivência dessa temática com o cotidiano e o futuro profissional, pôde-se inferir que os professores, provavelmente, não fazem uso de contextualização para aprofundar e dinamizar suas aulas ou que podem até fazer uso desse recurso, mas o utilizam simplesmente em nível de exemplificação.

Cabe salientar que a utilização da contextualização em nível de exemplificação provoca a falta de correlação dos mesmos com os conhecimentos prévios que eles possuem e, assim, não promove uma aprendizagem significativa com o cognitivo.

Todavia, fazer uso de contextualização no ensino de ciências é mais do que simplesmente dar exemplos do cotidiano, é promover o movimento de ciência-tecnologiasociedade-ambiente (CTSA) integrado aos conteúdos, buscando promover as reflexões mais críticas, aplicabilidade dos assuntos no cotidiano, bem como retomar e impulsionar a educação ambiental em sala de aula (SANTOS, 2007).

Apesar disto, este método didático, não pode ser visto como único e adequado para a aprendizagem de todos, pois cada um tem uma forma de aprender conforme sua especificidade. Mesmo assim, é importante realizar a avaliação da eficiência deste método, sabendo que corrobora com o processo de aprendizagem e dá significado aos assuntos socialmente.

Outrossim, foi observada a falta de aplicabilidade direta dos conteúdos de Química, tanto no cotidiano quanto no futuro profissional, o que impossibilita a compreensão e a reflexão crítica de um eventual fato e, consequente, ausência de tomada de ações para resolução.

Com a aplicação da técnica de evocação livre de palavras, constata-se a eficiência do método como ferramenta de coleta de informações. Norteando, assim, as aulas a serem ministradas, bem como na escolha de métodos didáticos que promovam uma aprendizagem 
significativa, na qual ocorram conexões dos conhecimentos científicos com os conhecimentos prévios dos educandos.

Nesse sentido, verificou-se que o desenvolvimento do método escolhido para ministrar as aulas permitiu a maior interação e participação de toda a turma de forma dialogada, levando os discentes a compreenderem a problemática da qualidade de água, refletindo criticamente e propondo alternativas para solucionar e melhorar as propriedades qualitativas e quantitativas da água, aspirando qualidade de vida.

Ao fim, para realizar um comparativo entre os conhecimentos prévios dos educandos com o que foi adquirido após a aplicação da metodologia, realizou-se novamente a aplicação da técnica de evocação livre de palavras para o termo "tratamento de água" com o intuito de examinar as representações sociais dos participantes e se sofreram influências.

Desse modo, após a aplicação da técnica realizou-se a contabilização para o referido termo motivador, obtendo $\mathrm{f}=4,50$ e $\mathrm{OME}=2,98$, classificando as palavras evocadas em concordância com a Tabela 3.

TABELA 3 - Classificação das palavras evocadas após aplicação da metodologia.(Fonte: Própria)

\begin{tabular}{|c|c|c|c|c|c|}
\hline \multicolumn{3}{|c|}{ ELEMENTOS CENTRAIS } & \multicolumn{3}{|c|}{ ELEMENTOS INTERMEDIÁRIOS } \\
\hline \multicolumn{3}{|c|}{ f $>4,50 \quad$ OME $<2,98$} & \multicolumn{3}{|c|}{ f $>4,50 \quad$ OME $>2,98$} \\
\hline Palavras & $\mathbf{F}$ & OME & Palavras & $\mathbf{f}$ & OME \\
\hline \multirow{6}{*}{$\begin{array}{c}\text { Estações } \\
\text { Química } \\
\text { Água } \\
\text { Saúde } \\
\text { Análise }\end{array}$} & \multirow{6}{*}{$\begin{array}{c}11 \\
9 \\
12 \\
8 \\
6\end{array}$} & \multirow{6}{*}{$\begin{array}{l}2,36 \\
2,33 \\
1,67 \\
2,63 \\
2,83\end{array}$} & Substâncias & 7 & 3,57 \\
\hline & & & Adsorção & 13 & 4,15 \\
\hline & & & Processos & 13 & 3,54 \\
\hline & & & Limpeza & 6 & 4,17 \\
\hline & & & Portaria & 5 & 3,00 \\
\hline & & & Potável & 5 & 3,40 \\
\hline \multicolumn{3}{|c|}{$\begin{array}{c}\text { ELEMENTOS } \\
\text { INTERMEDIÁRIOS }\end{array}$} & \multirow{2}{*}{\multicolumn{3}{|c|}{$\begin{array}{c}\text { ELEMENTOS PERIFÉRICOS } \\
f<4,50 \quad \text { OME }>\mathbf{2 , 9 8}\end{array}$}} \\
\hline \multicolumn{3}{|c|}{$\mathrm{f}<4,50 \quad \mathrm{OME}<2,98$} & & & \\
\hline Palavras & $\mathbf{F}$ & OME & Palavras & $\mathbf{f}$ & OME \\
\hline \multirow{6}{*}{$\begin{array}{c}\text { Vazão } \\
\text { Essencial } \\
\text { Purificação } \\
\text { Padronização } \\
\text { Investimentos }\end{array}$} & \multirow{2}{*}{1} & \multirow{2}{*}{2,00} & Reutilização & 2 & 3,00 \\
\hline & & & Carvão & 1 & 4,00 \\
\hline & 4 & $2, \angle J$ & Reservatório & 3 & 3,67 \\
\hline & 1 & 2,00 & Areia & 1 & 3,00 \\
\hline & 1 & 1,00 & Conscientização & 2 & 3,00 \\
\hline & 2 & 2,00 & Encanamento & 1 & 5,00 \\
\hline Oualidade & 2 & $\begin{aligned} 5,00 \\
5,50\end{aligned}$ & População & 1 & 5,00 \\
\hline Vida & 2 & 100 & Resíduos & 4 & 4,00 \\
\hline Natureza & & 200 & Mistura & 2 & 4,50 \\
\hline Natureza & 1 & 2,00 & Técnica & 1 & 4,00 \\
\hline
\end{tabular}


Analisando essa tabela e a evocada inicialmente para esse termo motivador, nota-se que diminuiu a quantidade de palavras distintas constituintes do núcleo central, inferindo que os estudantes tornaram-se mais específicos.

As representações sociais da turma como um todo depreenderam mais do que do senso comum que apresentavam inicialmente, agregando ao termo valor significativo da metodologia aplicada. Pois, confirma-se que os estudantes identificam mais do que onde ocorre o tratamento da água e para que serve.

A partir das palavras evocadas posteriormente a aplicação da metodologia, os discentes apresentaram frases melhor estruturadas, com argumentos mais esclarecidos e ligação para o termo que estão correlacionando. Entendendo que eles compreenderam que é preciso atribuir qualidade a água que se consome a fim de garantir boa qualidade de vida e evitar malefícios à saúde. Apresentando, assim, o conhecimento sobre a existência de padrões norteadores para o enquadramento da água e que para tanto é necessário à execução de análises.

Foi verificado a partir do método aplicado que os estudantes identificam os processos de tratamento das águas bem como cada etapa se processa, destacando que tal aprendizagem está correlacionada com os conteúdos da disciplina de Química.

\section{CONSIDERAÇÕES FINAIS}

A partir de distintos conhecimentos prévios e visões de mundo, as representações sociais servem como uma ferramenta de estudo para analisar questões educacionais quanto à aprendizagem.

Isso ocorre devido os educandos estarem em um meio com influências sócio-históricocultural, as quais modelam e definem as concepções acerca de uma determinada temática que os estudantes irão apresentar.

Analisando a aplicação inicial da técnica, constata-se que o professor não faz uso do método da contextualização para melhorar a aprendizagem significativa ou pode utilizar em nível de exemplificação de um eventual conteúdo no cotidiano do estudante, não proporcionando a reflexão crítica e ativa para compreensão do exemplo ilustrado. Assim, os educandos apresentaram concepções a respeito do termo sem ligação com o conhecimento científico.

A aplicação da metodologia teve seus objetivos alcançados quando intentou contextualizar conteúdos da disciplina de Química com a temática qualidade de água. Pois 
permitiu a participação ativa dos discentes durante a aula, tendo a ação e reflexão dos conteúdos, construindo e fortalecendo uma aprendizagem significativa.

Constatando que os conteúdos abordados foram bem desenvolvidos e contextualizados, pois foram empregados nas justificativas dos educandos na correlação das evocações realizadas no final, pois identificam e interpretam o senso comum que apresentaram inicialmente.

Tal método foi bastante aprovado pelos educandos, sendo, portanto, requisitado que mais aulas pudessem proporcionar a mesma abordagem. Na qual os mesmos veem aplicação direta dos conteúdos no cotidiano e futuro profissional. Dessa forma, sendo ativos na construção de valores necessários para a compreensão do que os cercam, podendo tomar decisões e atuar para solucionar, bem como divulgar tais conhecimentos.

Então, a representação social a partir da técnica de evocação livre de palavras funciona como um importante recurso avaliativo na área educativa, que pode ser usada de forma analítica para investigar o sistema de ensino adotado e a estrutura social em que estão inseridos os discentes, servindo para orientar e agregar valor a aula a ser ministrada com base no conhecimento prévio dos estudantes.

\section{REFERÊNCIAS}

AUSUBEL, David P. Aquisição e retenção de conhecimentos: uma perspectiva cognitiva. Lisboa: Plátano Edições Técnicas, $1^{a}$ edição, 2001.

COLL, C.; POZO, J. I. SARABIA, B.; VALLS, E. Os conteúdos na reforma: ensino e aprendizagem de conceitos, procedimentos e atitudes. Porto Alegre: Artes Médicas, 2000.

CORTES JÚNIOR, L. P. As representações sociais de "Química Ambiental": Contribuições para a formação de bacharéis e professores de Química. Dissertação (Mestrado). Universidade de São Paulo. São Paulo, 2008.

CORTES JUNIOR, L.P.; CORIO, P e FERNANDEZ, C. As representações sociais de Química Ambiental dos Alunos Iniciantes na Graduação em Química. Química Nova na Escola, vol. 31, nº 1, p.46 a 54, 2009.

FRANCO, M.L.P.B.; NOVAES, G. T. F. Os jovens do Ensino Médio e suas Representações Sociais. Cadernos de Pesquisa, ${ }^{\circ}$ 112, p. 167-183, março/2001.

GUARÁ, I. M. F. da R. Educação, proteção e muitos espaços para aprender. São Paulo: Cenpec, 2003.

JODELET, D. (Org.). As Representações Sociais. Rio de Janeiro: Ed. UERJ, 2001.

Représentations sociales: un domaine en expansion. In: JODELET, D. (Org.). Les représentations sociales. Paris, PUF, 1989. 
LISBÔA, J. C. F. Escolaridade e o antagonismo em Química: representações sociais da Química. Dissertação (Mestrado). Universidade de São Paulo, São Paulo, 2002.

SÁ, C.P. Núcleo das representações sociais. Petrópolis: Vozes, 1996.

SANTOS, W. L. P.; Contextualização no Ensino de Ciências por meio de temas CTS em uma perspectiva crítica. Ciência e Ensino. Número especial: "Educação em Ciência, Tecnologia, Sociedade e Ambiente", vol. 1, 2007.

SCHAFFER D. Z. Representações sociais de alunos universitários sobre o termo "Orgânico". Dissertação (Mestrado). Universidade de São Paulo, 2007. 